\title{
Effect of Network-Assisted Language Teaching Model on Undergraduate English Skills
}

\author{
Chunyan $\mathrm{He}^{1,2}$ \\ ${ }^{1}$ School of Humanities and Economic Management, China University of Geosciences (Beijing), Beijing, China \\ ${ }^{2}$ Department of Economics \& Finance, Texas A\&M University-Commerce, Commerce, USA \\ Correspondence: Chunyan He, School of Humanities and Economic Management, China University of \\ Geosciences (Beijing), Beijing, 100083, China. Tel: 86-134-2608-2819. E-mail: hcy82125@163.com
}

Received: March 21, 2013 Accepted: April 10, 2013 Online Published: May 8, 2013

doi:10.5539/elt.v6n6p29 URL: http://dx.doi.org/10.5539/elt.v6n6p29

\begin{abstract}
With the coming of the information age, computer-based teaching model has had an important impact on English teaching. Since 2004, the trial instruction on Network-assisted Language Teaching (NALT) Model integrating the English instruction and computer technology has been launched at some universities in China, including China university of Geosciences (Beijing) (CUGB). The purpose of this paper is to provide experimental evidence about whether NALT Model can enhance undergraduate English skills more effectively than the traditional teaching model. In this study, an experimental study is conducted to get the data (students' exam scores from experimental group and control group). Then a comparison method is utilized to analyze the experiment data that is the final examinations of every semester from the fall semester of 2005 to the fall semester of 2006 at CUGB. The results of a separate independent t-test demonstrate significant differences between experimental and control groups in mid-test and post-test with SPSS 11.5. Then a graphical model $\bar{X}-S$ Plane Analysis Model (Li \& Xie, 1994) is used to analyze the statistical characteristics of both groups' scores. The results show that the whole distribution of the experimental group's scores in the post-test is totally in the best state. Above study results indicate NALT model is indeed more effective than the traditional classroom teaching model in improving undergraduate English skills. This study contributes to the better realization of the effect of NALT model, and urges researchers to deepen the study of this field in future.
\end{abstract}

Keywords: Network-Assisted Language Teaching Model, undergraduate English skills, experimental study, comparison method, t-test, $\bar{X}-S$ Plane Analysis Model

\section{Introduction}

Recently, the study of cognitive psychology has showed the human learning process is what "learning cannot be done to or for learners; it can only be done by themselves" (McDonough \& Shaw, 2003). A theory of developing learner autonomy is proposed to show the nature of learning. In China, however, TEFL has been continuously criticized for its low-efficiency, particularly for college English teaching. Therefore, there is an urgent need for the reform of college English teaching. With the coming of the information age, computer has had an important impact on English teaching. Thus the traditional classroom teaching model is gradually replaced by a new English teaching model integrating computer technology. In the recent years, computers have been regarded as the integral part of technology and they have played their crucial role in promoting effective instruction (Sadeghi \& Dousti, 2013). 


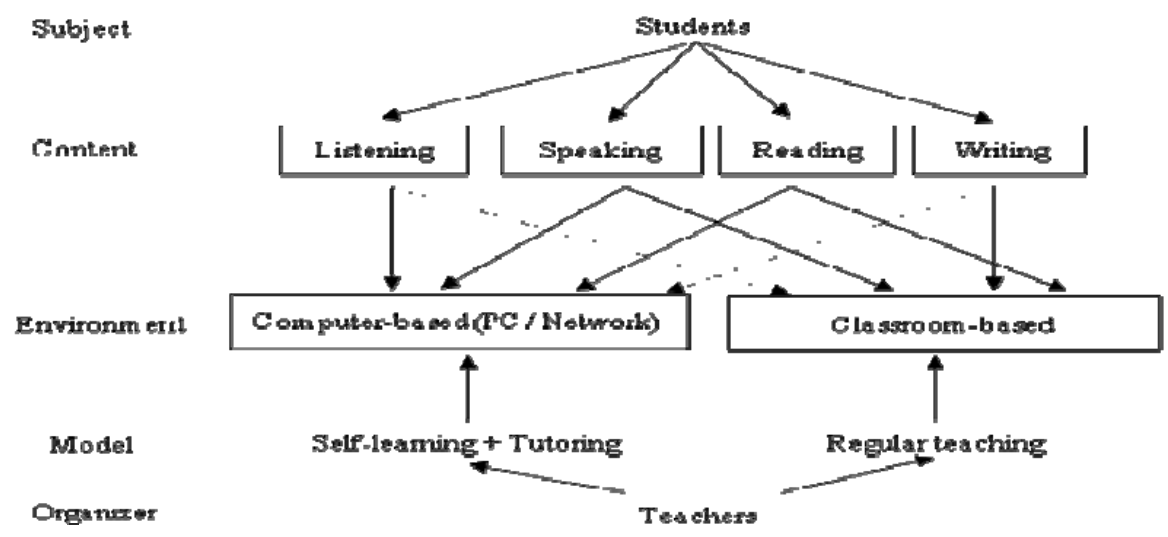

Figure 1. College English NALT Model (Wu, 2006, revised)

Since 2004, the trial teaching on a new teaching model integrating the English instruction and computer technology has been launched at some universities in China. This new teaching model is Network-assisted Language Teaching Model (NALT Model) as Figure 1. As an emerging technology-based approach, it is thought as a good method that "can present opportunities for learners to study on their own, independent of a teacher and can also offer opportunities for learners to direct their own learning" (Beatty, 2010).

China university of Geosciences (Beijing) (CUGB) has adopted NALT Model in several classes since the fall semester of 2004. In these classes, students spend half of all English class hours at computer labs and half in the classroom. Teachers bring in the new textbooks "New Perspective College English" and "New Horizon College English" published by Shanghai Foreign Language Education Press and their network learning platform called "New Perspective English Learning System" and "New Horizon English Learning System" to use this new teaching model effectively. The former is used to train students' listening and speaking and the latter is to train their reading and writing. Both Systems have some characteristics as follows:

1) They contain such media as graphics, texts, sounds and video in the exercises. The sounds and graphics are very clear due to the adoption of digital technology in audio frequency and video frequency.

2) In the listening part, all the exercises have got hints and script, which makes it possible for students to be self-paced and get immediate feedback. Furthermore, there are several explanations to the new words, which help them do the listening exercises more easily and master new words in listening. Meanwhile, the listening exercises are designed from easy to difficult, which help students enhance confidence and develop their listening gradually. On the other hand, in the speaking part, several related culture backgrounds are provided to understand through words and graphics. The vivid video can stimulate students' learning interest. The recording is made by British and American teachers, so the students can be exposed to various different pronunciation and intonation, which is suitable for real life communication. Students can simulate the dialogues of this system and reproduce a new one to exercise with their partners.

3) In the reading part, more background material is provided. Some important knowledge points are explained, and as long as students click the words or sentences with the related explanations, the contents of certain knowledge points will appear nearby. The whole text can be read by the system so that students can learn the text while listening the recording. Furthermore, the whole text has the Chinese translation so that students can refer to its Chinese translation when they cannot understand the meaning of the text.

4) As to the feedback, students can communicate with teachers through E-mail of this system in time. In the "community communication" of this system, students can interact with teachers, including receiving learning tasks showed by teachers, asking questions, handing in assignments, and bringing up learning suggestions and so on. Furthermore, this system designs a series of tests for students' self-assessment and teachers' teaching assessment. The result of every test is showed with charts, which makes teachers understand students' learning situation more directly. 


\section{Literature Review, Study Purpose and Significance}

\subsection{Definition of CALL}

According to Beatty (2010), CALL can be defined either as "a direct activity through structured lessons or during an activity peripheral to the study of language but that, nonetheless, promotes language awareness and acquisition". In general, CALL is the integration of computer applications with language teaching and learning.

Recently, this field has gone by a number of different names because of the different research emphases, such as CAI, CAL, CALI, and NALT etc. However, CALL is still the generic term. This paper mainly studies one form of CALL, i.e. NALT.

\subsection{The Current State of Studies on CALL}

NALT, as a new teaching model, has been used widely in the Chinese undergraduate English teaching. However, the experimental research on this model is deficient. Most researchers made a great number of studies about CALL but not NALT.

Since the late of 1950s, the research and practice on CALL have appeared in the West. There have been some fruitful studies on CALL which focus on course / curriculum development issues and instructional efficacy from the perspectives of faculty and administration. In general, these studies stress the benefits and advantages of computer-based technology for instructional uses, such as Peterson's Language Teaching and Networking (1997) which points out that "the computer and web give the learners a better learning environment by providing them with pictures, words, sound, and situations close to real life".

In China, the research on CALL began in 1970s, and NALT only appeared at the latest ten years, thus the study field on NALT is still a new one. Of the CDMD and CJFD for the keywords "network teaching" over the dates 2005 to 2013, CNKI provides the most responses: 13493 of which 1 372articles (10\%) are related to the English teaching. This proportion is relatively low than the research on other subjects. Obviously, these data show that the study of NALT on English teaching is deficient.

At latest years, some articles related to study of NALT model have been published with the development of college English teaching reform.

From the study contents, some articles tend to study learner autonomy under NALT. For example, in 2005, the researchers from 23 universities of the whole country respectively made reports on NALT model and these reports have been collected into the book edited by Zhuang (2005). Their study results show that NALT has the significant effect on College English skills development. However, most researchers just did the research in one year or even only half year, which makes the low reliability of their study data. Moreover, the analysis only focuses on the whole effect but not deepen to study the subjects' characteristics. Other articles focus on the effect on one English skill's improvement, such as listening (Zhong, 2012) and writing skills (Zhou \& Xiao, 2012). But they have not assessed the effect on the comprehensive English skills overall.

From the study methods, most articles always are limited to use qualitative analysis, such as the literature research method. Researchers designed some questionnaires to survey the effect of NALT model. Thus, the survey results always mix much subjective emotion, which well may be far away the true study results.

\subsection{Study Purpose and Significance}

According to the background and literature review of this theme, this paper will use the quantitative analysis method experimental method and comparison method to test the effect of NALT on undergraduate English skills of CUGB. The experiment period is 3 semesters which is long enough to the data collection. Furthermore, the paper will analyze the statistical characteristics of subjects' scores, which is the highlight of this paper and meanwhile can contribute to expose the reasons why NALT Model can enhance undergraduate English skills more / less effectively than the traditional teaching model. In all, the purpose of this paper is to provide experimental evidence about whether NALT Model can enhance undergraduate English skills more effectively than the traditional teaching model.

This study can enrich the theories of EFL teaching methods, to a certain extent. Meanwhile, it also can help teachers choose more effective teaching model to raise the college English teaching quality.

\section{Methods}

In this study, a teaching experiment is conducted to get the data (students' exam scores from experimental group and control group). Then a comparison method is utilized to analyze the experiment data. Through the experiment, the author got three sets of data that is the final examinations of every semester from the fall 
semester of 2005 to the fall semester of 2006 at CUGB. The aim of all the tests is to assess students' comprehensive English skills (including listening, speaking, reading and writing).

\subsection{Context}

The investigation is conducted in the context of a network-assisted college English course which has been held in multimedia lab and traditional classroom since the fall semester of 2005. It is conducted by teachers from the English Department. Students of experimental group take the English class in the lab once a week through a new added network system called New Perspective \& Horizon English Learning System. The course lasts about 16 weeks every semester. The multimedia lab is open during regular office hours in the daytime and on five evenings a week. Therefore, students have enough time to learn English in the lab.

The textbooks are "New Perspective College English" and "New Horizon College English" published by Shanghai Foreign Language Education Press. The network systems are New Perspective English Learning System and New Horizon English Learning System.

\subsection{Subjects}

The subjects include 140 sophomores of non-English major from CUGB. These sophomores are divided into two groups: experimental group (60 students) which learns English in NALT model, and control group (80 students) which is taught with the traditional classroom instruction model.

Table 1. Subjects Characteristics

\begin{tabular}{|c|c|c|c|c|c|c|}
\hline Group & Number & $\begin{array}{l}\text { School } \\
\text { Department }\end{array}$ & and & $\begin{array}{l}\text { Teaching material } \\
\text { (textbook) }\end{array}$ & $\begin{array}{l}\text { Class } \\
\text { hours } \\
\text { week }\end{array}$ & $\begin{array}{l}\text { Teachers' } \\
\text { titles }\end{array}$ \\
\hline $\begin{array}{l}\text { Experiment } \\
\text { al group }\end{array}$ & $60(30+30)$ & $\begin{array}{l}\text { School } \\
\text { Engineering } \\
\text { Technology }\end{array}$ & $\begin{array}{l}\text { of } \\
\text { and }\end{array}$ & New Perspective & & \\
\hline $\begin{array}{l}\text { Control } \\
\text { group }\end{array}$ & 45 & $\begin{array}{l}\text { School of the } \\
\text { Science } \\
\text { Resources } \\
\text { School of } \\
\text { Science } \\
\text { Technology }\end{array}$ & $\begin{array}{l}\text { Earth } \\
\text { and } \\
\text { Land } \\
\text { and }\end{array}$ & $\begin{array}{l}\text { College English } \\
\& \\
\text { New Horizon } \\
\text { College English }\end{array}$ & $\begin{array}{l}180 \\
\text { minutes }\end{array}$ & lecturer \\
\hline
\end{tabular}

Table 1 gives a detailed description about the sample. From Table 1, it shows that both groups have the same English learning context, including textbook, class hours, teachers' titles, and the same teacher in each group.

Although most of the English learning context of these two groups is roughly the same, it is still necessary to do a further survey through analyzing the scores of the college entrance examination in order to make sure that the original English proficiency would not become an interfering factor to the study. Therefore, all subjects' English scores in their college entrance examination are retrieved and analyzed. The results are that the average passing percentage of each group is $78.67 \%$ (experimental group) and $78.89 \%$ (control group). That is to say, the total sample has the same English proficiency before the experiment.

A series of investigations show that the subjects in both groups selected as sample have the same or similar English learning context and English proficiency before the experiment begins. Thus, the study results of this experiment will have higher reliability.

\subsection{Data and Instruments}

In this study, three tests are conducted and the scores are used for the experimental data. These tests are all the final examinations of every semester from the fall semester of 2005 to the fall semester of 2006 and are respectively named pre-test (fall semester of 2005), mid-test (spring semester of 2006), and post-test (fall semester of 2006) which are similar in exam form. All these examinations test students' comprehensive language competence (including listening, speaking, reading and writing). And the contents of each test are the same between experimental group and control group.

This study uses the experimental study method and contrastive analysis method. The data are analyzed using the SPSS 11.5 (Statistic Package for Social Science). The contrastive analysis results can be gotten using a separate independent t-test. Then a graphical model $\bar{X}-S$ Plane Analysis Model (Li \& Xie, 1994) is used to analyze the 
statistical characteristics of both groups' scores in order to confirm NALT Model's effectiveness in further.

\section{Comparisons of Both Groups' Scores of Pre-test Mid-test and Post-test}

\subsection{The Reliability of the Tests}

Before the comparisons, a check for the reliability of the three tests should be done to ensure the experimental results' reliability.

Table 2. Reliability of the Three Tests

\begin{tabular}{|c|c|c|c|c|}
\hline & & pre-test & mid-test & post-test \\
\hline \multirow[t]{2}{*}{$\mathrm{N}$} & Valid & 140 & 138 & 139 \\
\hline & Missing & 0 & 2 & 1 \\
\hline \multicolumn{2}{|c|}{ Mean } & 56.6964 & 63.0616 & 65.9604 \\
\hline \multicolumn{2}{|c|}{ Median } & 56.0000 & 63.0000 & 68.0000 \\
\hline \multicolumn{2}{|c|}{ Mode } & 49.00 & 63.00 & 70.00 \\
\hline \multicolumn{2}{|c|}{ Std. Deviation } & 12.35196 & 10.07245 & 11.10899 \\
\hline \multicolumn{2}{|c|}{ Skewness } & -.117 & -.424 & -1.118 \\
\hline \multicolumn{2}{|c|}{ Std. Error of Skewness } & .205 & .206 & .206 \\
\hline \multicolumn{2}{|c|}{ Kurtosis } & .345 & -.248 & 2.039 \\
\hline \multicolumn{2}{|c|}{ Std. Error of Kurtosis } & .407 & .410 & .408 \\
\hline \multicolumn{2}{|c|}{ Range } & 68.50 & 47.00 & 65.00 \\
\hline \multicolumn{2}{|c|}{ Minimum } & 18.50 & 38.00 & 20.00 \\
\hline \multicolumn{2}{|c|}{ Maximum } & 87.00 & 85.00 & 85.00 \\
\hline
\end{tabular}

In order to make sure whether these three tests are reliable or not, SPSS is employed to analyze the scores. The detailed analysis is presented in Table 2 .

Table 2 shows that the Skewness values and the Kurtosis values are -0.117 and 0.345 respectively in the pre-test and -0.424 and -0.248 in the mid-test. Their absolute values are all extremely close to 0 . Therefore, the scores in the pre-test and mid-test are both in the state of normal distributions. Besides, the Skewness values and the Kurtosis values are -1.118 and 2.039 respectively in the post-test, whose absolute values are not close to 0 ; however, their mean (65.960 4), median (68) and mode (70) are extremely close. Therefore, the scores in the post-test still can be regarded as the normal distributions. Thus, the above analyses verify that the three tests are reliable.

\subsection{Contrastive Analyses and Discussion}

After verifying the reliability of the scores of these three tests, a series of contrastive analyses are carried out.

\subsubsection{T-test of Both Groups' Scores}

The comparisons of all the subjects' scores of the three tests between the experimental group and control group are conducted to assess the learning effects of both groups with different teaching models.

Statistical tests are applied to determine whether or not there are significant overall differences in subjects' scores between the both groups. The significance level is set at $a \prec 0.05$. In the current research, SPSS is employed to conduct the T-test for independent samples (i.e. parametric statistical test) of the three tests' scores of both groups because the variables (scores) are interval and the groups are independent.

Table 3. T-test of the Pre-test's Scores

\begin{tabular}{llllll}
\hline & & \multicolumn{2}{l}{ Levene's Test for Equality of Variances } & \multicolumn{2}{l}{ t-test for Equality of Means } \\
\hline & & F & \multirow{2}{*}{ Sig. } & Sig. (2-tailed) & Mean \\
Difference \\
\multirow{2}{*}{ Score } & & .588 & .126 & -3.23125 \\
& $\begin{array}{l}\text { Equal variances assumed } \\
\text { Equal variances not assumed }\end{array}$ & 0.295 & & .131 & -3.23125 \\
\hline
\end{tabular}

In the part of Levene's Test for Equality of Variances shown in Table 3, it presents $F=0.295$, Sig. $=0.588 \succ 0.10$, so the variances in the populations from which the samples are derived possess homogeneity. Therefore, only the 
data from the row of Equal variances assumed should be viewed. This row shows that $F=0.295$, Sig. $(2-$ tailed $)=0.126 \succ 0.05$, so null hypothesis cannot be rejected. Moreover, the mean difference is the negative in Table 3, which means the mean score of the group 1 (experimental group) is lower than of the group 2 (control group) by about three points (Mean Difference is -3.231 25). Therefore, it is indicated that both groups show no significant difference in this pre-test at 5 per cent level.

Table 4. T-test of the Mid-test's Scores

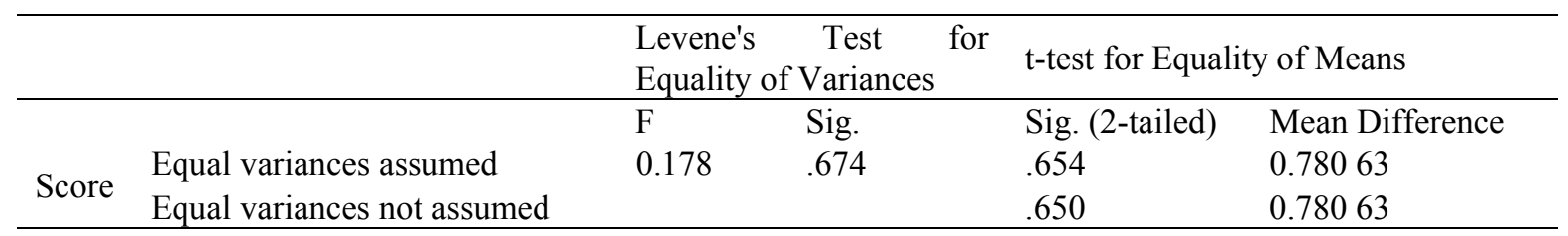

In the part of Levene's Test for Equality of Variances shown in Table 4, it presents $F=0.178$, Sig. $=0.674 \succ 0.10$, so the variances in the populations from which the samples are derived possess homogeneity. Therefore, only the data from the row of Equal variances assumed should be viewed. This row shows that $F=0.178$, Sig. $(2$-tailed $)=0.654 \succ 0.05$, so null hypothesis cannot be rejected. Therefore, it is indicated that both groups show no significant difference in this mid-test at 5 per cent level.

Furthermore, compared with the significance of the pre-test, due to Sig. $($ pre-test $)=0.126 \prec$ Sig. (mid - test $)=0.645$, it means that the difference in the scores of mid-test from both groups is less significant than of the pre-test. On the other hand, the mean score of the group 1 (experimental group) is lower than of the group 2 (control group) in the pre-test; however, the mean score of the group 1 becomes higher than of the group 2 in the mid-test by around one point (Mean Difference is 0. 780 63). Above results indicate that the English achievements of experimental group in NALT model have been gradually improving in the fall semester of 2005.

Table 5. T-test of the Post-test's Scores

\begin{tabular}{llllll}
\hline & & \multicolumn{2}{l}{$\begin{array}{l}\text { Levene's Test for Equality of } \\
\text { Variances }\end{array}$} & & \multicolumn{2}{l}{ t-test for Equality of Means } \\
\hline & & F & Sig. & Sig. & Mean \\
(2-tailed) & Difference \\
\multirow{2}{*}{ Score } & Equal variances assumed & 11.672 & .001 & .000 & 9.11917 \\
& Equal variances not assumed & & & .000 & 9.11917 \\
\hline
\end{tabular}

In the part of Levene's Test for Equality of Variances shown in Table 5, it presents $F=11.672$, Sig. $=0.001 \prec 0.10$, so the variances in the populations from which the samples are derived do not possess homogeneity. Therefore, only the data from the row of Equal variances not assumed should be viewed. This row shows that $F=11.672$, Sig. $(2$-tailed $)=0.000 \prec 0.05$, so null hypothesis cannot be rejected absolutely. Therefore, it is indicated that both groups show significant difference in this post-test at 5 per cent level. Furthermore, the mean difference is the positive, that is, the mean score of the group 1 (experimental group) is higher than of the group 2 (control group) by about nine points (Mean Difference is 9.119 17). Therefore, it is claimed that the English achievements of experimental group in NALT model achieved significant progress after three semesters' English learning, compared with of the control group in the traditional classroom teaching model.

\subsubsection{Analysis of the Statistical Characteristics of Both Groups' Scores}

After comparing the three scores of both groups, the further investigations on the statistical characteristics of both groups are carried out. Here, the $\bar{X}-S$ Plane Analysis Model (Li \& Xie, 1994) is quoted to do the research. In this model, the symbol $\bar{X}$ is the mean value which is the most important measure of central tendency. And the symbol $S$ means the standard deviation which is "the most widely used measure of variability for variables with an interval or ratio level of measurement" (Butler, 1985). In other words, standard deviation is used to measure the degree of dispersion of variables. Therefore, the bigger the value of standard deviation is, the bigger the degree of dispersion of the frequency distribution of these variables. The both measures are used to describe the distribution characteristics of the variables. 
Table 6. Means and Standard Deviations of Both Groups' Scores in the Three Tests

\begin{tabular}{llll}
\hline Test & Group & Mean $(\bar{X})$ & Standard deviation $(S)$ \\
\hline \multirow{2}{*}{ Pre-test } & 1 & 54.8500 & 12.94555 \\
& 2 & 58.0813 & 11.77947 \\
\multirow{2}{*}{ Mid-test } & 1 & 63.5085 & 9.61388 \\
& 2 & 62.7278 & 10.45006 \\
\multirow{2}{*}{ Post-test } & 1 & 74.5254 & 7.23105 \\
& 2 & 65.4063 & 12.13560 \\
\hline
\end{tabular}

Note: group 1 is the experimental group; group 2 is the control group.

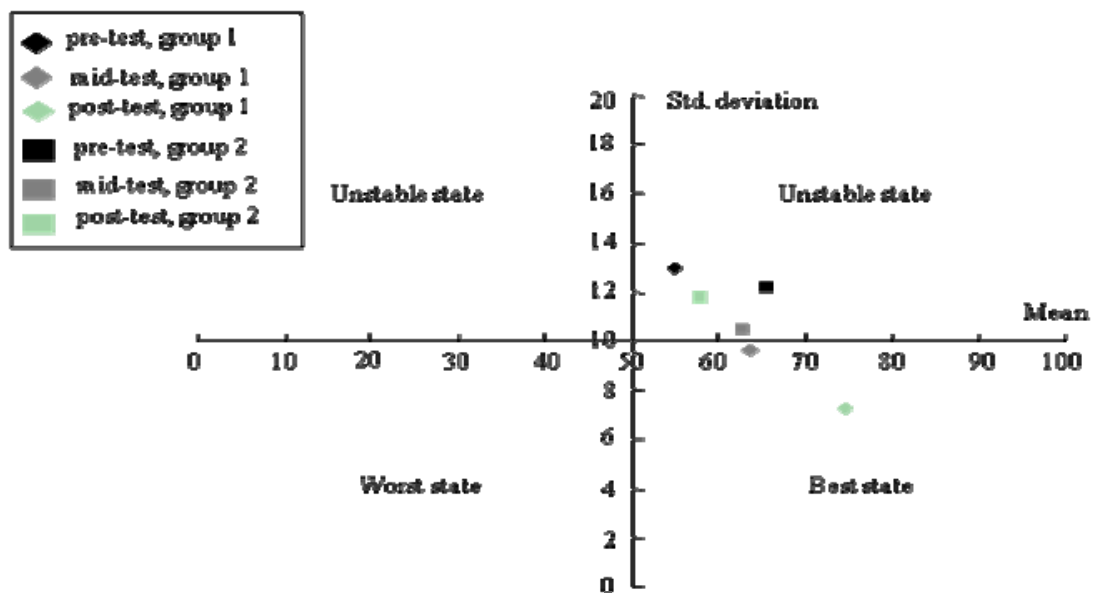

Figure 2. $\bar{X}-S$ Plane Analysis Model of Both Groups

The mean values and standard deviations of both groups' three tests shown in Table 6 are gotten with SPSS 11.5. When these mean values $(\bar{X})$ and standard deviations $(S)$ in Table 6 are put into the $\bar{X}-S$ Plane Analysis Model, statistical characteristics of both groups' scores are illustrated clearly as Figure 2.

From Figure 2, firstly, it is easy to find four states are respectively located in the four quadrants. In the first quadrant, the mean level of the scores is high, but the tendency is discrete, which means that some extremely low scores exist. In the second quadrant, the mean level of the scores is low and the tendency is also discrete, which means some extremely high scores exist. Thus, the whole distribution of the scores in the first and second quadrant is both in the unstable state. And the whole distribution of the scores in the third quadrant is in the worst state since the mean level of the scores is low but the tendency is relatively central. That is to say, these scores whose whole distribution is in the third quadrant are all low and there is not any extremely high score. In the fourth quadrant, the mean level of the scores is high and the tendency is relatively central; therefore, these scores whose whole distribution is in the fourth quadrant are all relatively high and the differences of their scores are small.

In the pre-test, the intersections of the values of both groups (i.e. two black points in Figure 2) are both in the first quadrant, which indicates that the whole distributions of both groups' pre-test scores are both in the unstable state. Furthermore, the whole distribution of the scores of the experimental group's scores is a little more unstable than of the control group's since its mean value is lower but the value of standard deviation is bigger than of the control group.

In the mid-test, the intersections of the values of both groups (i.e. two dark gray points in Figure 2) are respectively in the first (the control group) and the fourth (the experimental group) quadrants. It means that the whole distributions of the control group's scores is still in the unstable state, whereas of the experimental group's scores is in the best state. In this test, their mean values and the values of standard deviation are similar; and the value of standard deviation from the experimental group is a little smaller $(9.61388)$ so the whole distributions of the experimental group's scores exactly reaches the best state. 
In the post-test, the intersection of the values from the experimental group (i.e. the diamond light grey point in Figure 2) is totally in the fourth quadrant whereas of the values from the control group (i.e. the square light grey point in Figure 2) is still in the first quadrant. Thus the situation indicates that the whole distribution of the experimental group's scores is in the best state obviously, whereas of the control group's scores is in the more unstable state than in the mid-test because the bigger degrees of dispersion. In this test, the mean level of the experimental group's scores is high and the tendency is relatively central; that is, almost students of this group achieve the relatively high scores and the differences of their scores are small. Although the mean level of the control group is also high, there are some low-proficiency students in the control group so that the whole distributional tendency is discrete. Furthermore, comparing with of the experimental group, the mean level of the control group is still lower. Therefore, the whole distribution of the experimental group's scores in the post-test is more ideal and more close to the best state.

By comparison with of the pre-test's scores, the whole distributions of the mid-test's scores from both groups are both improved. Their mean levels raise and degrees of dispersion decline. Especially of the experimental group, the degree of dispersion falls more so that its whole distribution exactly reaches the best state. However, in the post-test, the whole distributions from these two groups have the significant difference. With the enormously raised mean level and fallen degrees of dispersion greatly, the whole distribution of the experimental group's scores in the post-test is totally in the best state. The situations from the experimental group indicate that NALT model is certainly better than the traditional classroom teaching model in improving students' whole English skills.

\section{Conclusion}

According to the results above, the English achievements of experimental group in NALT model achieved significant progress after three semesters' English learning, compared with of the control group in the traditional classroom teaching model. Furthermore, since the whole distributions of the experimental group are developed from the unstable state of pre-test to the best state of post-test while of the control group is always in the unstable state during those three tests, so NALT model used to the experimental group is certainly better than the traditional classroom teaching model used to the control group in improving students' whole English skills. Therefore, it is confirmed that NALT model indeed improves undergraduate English skills more effectively, according to above study results.

From the research method, this paper uses an experimental method to test and analyze the effect of this new teaching model. So the data from this quantitative analysis method are more credible and authentic. Furthermore, analysis of the statistical characteristics of both groups' scores using $\bar{X}-S$ Plane Analysis Model testifies the effectiveness of NALT Model further. It is the first time that we add $\bar{X}-S$ Plane Analysis Model into this experimental method, which is a great breakthrough to analysis methods of experimental research data. From the research contents, this paper conducts an overall assessment on the effect of this new teaching model on undergraduate English skills. An analysis of the statistical characteristics of both groups' scores is unique for the study of this field. Meanwhile, the experiment period is long enough to get the more scientific and credible data.

Of course, there are still some defects in this experiment. For example, the size of the total sample is a bit small compared with the total student number. However, this study can contribute to the better realization of the effect of NALT model, and urge researchers to deepen the research of this field in future.

\section{Acknowledgements}

I would like to express my great appreciation to School of Foreign Languages of CUGB for the research data provided to me.

\section{References}

Beatty, K. (2010). Teaching and Researching Computer-assisted Language Learning (2nd ed.). London: Pearson Education.

Butler, C. (1985). Statistics in Linguistics. Oxford: Basil Blackwell.

Li, K. D., \& Xie, Y. R. (1994). Multimedia-based Integrated Instructional Design. Beijing: Science Press. (in Chinese)

McDonough, J., \& Shaw, C. (2003). Materials and Methods in ELT: A Teacher's Guide (2nd ed.). Oxford: Blackwell Publishing Ltd.

Peterson, M. (1997). Language Teaching and Networking. System, 25(1), 29-37.

Sadeghi, K., \& Dousti, M. (2013). The Effect of Length of Exposure to CALL Technology on Young Iranian 
EFL Learners' Grammar Gain. English Language Teaching, 6(2), 14-26. http://dx.doi.org/10.5539/elt.v6n2p14

Wu, Y. J. (2006). On College English Teaching Model in the View of New Curriculum Requirements. Master Thesis. Northeast Normal University, Changchun. (in Chinese)

Zhou, S. L., \& Xiao, F. (2012). A Study on Error Correction Mode in College English Writing Teaching Through an Online Practice Platform. Journal of Chongqing University of Technology (Social Science), 12, 97-102. (in Chinese)

Zhong, W. X. (2012). Research on the Wed-based Autonomous Learning in Teaching College English Listening. Journal of Chengdu University of Traditional Chinese Medicine (Educational Science Edition), 4, 40-42. (in Chinese)

Zhuang, Z. X. (2005). Pilot Experimental Study Report on the National New Concept College English Network Teaching. Shanghai: Shanghai Foreign Language Education Press. (in Chinese) 